

\section{SOBRE UMA HISTÓRIA SOCIAL DO TRABALHO E DOS TRABALHADORES EM ANGOLA}

ALFAGALI, Crislayne Gloss Marão. Ferreiros e fundidores da Ilamba. Uma história social da fabricação de ferro e da Real Fábrica de Nova Oeiras (Angola, segunda metade do século XVIII). Luanda: Fundação Dr. António Agostinho Neto, 2018. 472p.

A obra Ferreiros e fundidores da Ilamba, da historiadora Crislayne Alfagali, analisa de forma minuciosa a história social dos ferreiros e fundidores no contexto da instalação e funcionamento da fábrica de ferro de Nova Oeiras, em Ilamba, Angola, na segunda metade do século XVIII. Mas se engana quem acha que este é mais um trabalho sobre a fábrica de ferro, tida por muito tempo pela historiografia estadonovista portuguesa como o grande feito do governador d. Francisco Inocêncio de Sousa Coutinho (1764-1772). ${ }^{1} \quad$ Aqui os

1 Vide, entre outros, Jofre Amaral Nogueira, Angola na época pombalina: o governo de Sousa Coutinho, Lisboa: s/l, 1960; protagonistas são os trabalhadores da Ilamba, quer dizer, trata-se de uma história social de trabalhadores africanos. Segundo a autora, seu interesse é inverter o foco da análise ao abordar o "tema da fábrica de ferro a partir das determinações locais, das escolhas das lideranças africanas” (p. 26).

Com grande rigor teórico e metodológico, Alfagali faz um exame cuidadoso de séries documentais diversas, em sua maior parte inéditos

Ralph Delgado, "O governo de Sousa Coutinho em Angola”, Stvdia, n. 6 (1960), pp. 1956; n. 7 (1961), pp. 49-66; n. 10 (1962), pp. 7-47; Gastão de Sousa Dias, D. Francisco Inocêncio de Sousa Coutinho: administração pombalina em Angola, Lisboa: Editorial Cosmos, Cadernos Coloniais n. 27, 1936, pp. 3-64. 
e dispersos em acervos do Brasil, de Portugal e de Angola, tais como correspondências entre o governo de Angola e a Secretaria de Estado da Marinha e Domínios Ultramarinos, bandos, portarias, registros iconográficos etc.. Aliás, vale destacar que as fontes iconográficas não estão presentes no livro como ilustração, pois a autora as utiliza como verdadeiros registros históricos, fontes que descortinam detalhes sobre as povoações, técnicas e ferramentas utilizadas pelos trabalhadores. Por meio de plantas, desenhos e fotografias, o edifício, que hoje está em ruínas, ganha vida e dá a conhecer importantes detalhes do empreendimento. Ademais, todos os documentos foram lidos partir de uma perspectiva que preconiza a experiência na região dos ambundos. Importante ainda é o diálogo estabelecido com obras de referência, mas oferecendo instrumentos analíticos aos que vislumbram novas possibilidades de pesquisa em história da África, em história social do trabalho, da produção de metais, entre outros temas.

De narrativa fina e envolvente, a obra de Crislayne Alfagali se inicia com a história de Pedro Manoel, fundidor ambundo que viveu no interior de Angola no século XVIII. Pedro Manoel foi um dos homens que trabalhou na Casa de Fundição dos Pretos, um edifício construído “à sombra da grande fábrica” (p. 164), mas que, mesmo sendo considerado um prédio menor, produziu todo o ferro de Nova Oeiras. A Casa de Fundição dos Pretos foi edificada a fim de o governador de Angola tentar regular as relações de trabalho dos "filhos" (termo que indica dependentes em geral) dos sobas. A tentativa, segundo a autora, fracassou, sobretudo porque os potentados da Ilamba conseguiram manter o domínio sobre seus dependentes. Ali os centro-africanos trabalharam e empregaram suas técnicas de fundição de ferro.

Não é por acaso que a autora inicia sua obra com aquele personagem. Sua escolha se relaciona justamente com o foco sobre os trabalhadores ambundos. Mas a ênfase sobre os trabalhadores locais não significa ignorar a presença de trabalhadores biscainhos, portugueses, brasílicos e franceses, cujas respectivas técnicas foram também rigorosamente detalhadas na obra. Trazer à luz outros fundidores 
permitiu a Alfagali comprovar que as técnicas de fundição ambundas foram as mais frutíferas na fabricação de ferro.

Nos cinco capítulos do livro, Crislayne Alfagali buscou reconstruir os processos históricos que envolveram a fabricação de ferro na região. O primeiro capítulo alude à geografia e à demografia do que se chamava Reino de Angola no século XVIII, locus marcado por tensões políticas e de frágil presença europeia. Nesse sentido, a própria fábrica de ferro é compreendida como uma tentativa de ampliar a administração lusa, na medida em que os sobas, principais lideranças da estrutura política ambunda, seriam obrigados a fornecer trabalhadores, escolhidos entre seus dependentes, para a fábrica. No entanto, como a cartografia da época evidencia, até pelo menos finais do XVIII era ínfimo o conhecimento e a apropriação do território pelos portugueses, o que indica que um dos maiores objetivos das reformas pombalinas, transformar o Reino de Angola em um território contínuo, não se efetivou. A soberania dos sobas persistiu e Angola permaneceu como um “triângulo descontínuo” (p. 42).
É por aí que a autora perscruta os já muito manuseados tratados de vassalagem (contratos de deveres e obrigações firmados entre sobas africanos e autoridades portuguesas), mas lendo-os de forma inovadora. Por meio deles, a autora pretendeu compreender a obrigatoriedade da prestação de serviços por parte dos sobas avassalados. Ao cruzar nomes de sobas presentes na História Geral das Guerras Angolanas, no Livro dos Baculamentos, ambos documentos do século XVII, com um inventário feito sob ordem do governador Sousa Coutinho no século XVIII, entre outras fontes, a autora constata que muitos sobas tinham uma longa relação com os portugueses e faziam alianças que objetivavam manter sua autonomia. ${ }^{2}$

Porém, a exploração das minas de ferro pelos ambundos era mais longeva do que a relação dos

2 Antônio de Oliveira de Cadornega, História geral das guerras angolanas, Lisboa: Agência Geral do Ultramar, 1972; e Aida Freudenthal, Selma Pantoja (eds.), Livro dos Baculamentos, que os sobas deste Reino de Angola pagam a Sua Majestade (1630), Luanda: Ministério da Cultura e Arquivo Nacional de Angola, 2013. 
centro-africanos com os portugueses, assunto desenvolvido no segundo capítulo. Neste, Alfagali contempla mais detalhadamente a região das minas de ferro a partir das diferentes perspectivas que os centro-africanos e os europeus tinham do recurso natural. Muito antes das iniciativas portuguesas para erigir as fábricas de ferro, vigorava a atividade mineradora levada a cabo pelos chefes locais da região da Ilamba e do Lumbu. Por isso, não à toa Nova Oeiras seria construída nas terras do soba Nguengue a Kimbemba, jurisdição de Massangano, local onde era possível encontrar o minério na superfície da terra. Observando a acepção da palavra nguengue, que significa pessoa de grande influência, Alfagali levanta a hipótese de que o título político se relacionava ao controle das minas de ferro. Complementarmente importante é o arrolamento dos sobas das jurisdições de Ambaca, Golungo, Cambambe e Massangano, cujos dependentes eram especializados no trabalho com o ferro. Assim, a autora corrobora a hipótese de que havia uma tradição mineradora e fabril na região da Ilamba e que o empreendimento do governador português Sousa
Coutinho apenas buscou explorar uma indústria ${ }^{3}$ já consolidada entre os centro-africanos.

O controle das minas pelos ambundos e a posse de terra pelos sobas da região levaram a tensões quando o governo português pretendeu instalar a fábrica de ferro, posto que havia controvérsia em torno dos objetivos africanos e portugueses na fabricação de produtos de ferro. Por um lado, os portugueses visavam explorar a tecnologia com fins de mercado, a exemplo da fabricação de grilhões amplamente utilizados no tráfico de escravizados. Paralelamente, a fabricação de armas também era crucial porque fazia parte do projeto político de expansão e manutenção da monarquia lusa. Por outro lado, para os centro-africanos, a produção do ferro não se desvinculava de aspectos religiosos e políticos. Algumas armas tinham uso ritual, como a machadinha que servia de emblema linhageiro do Ngola.

Alfagali antecipa uma crítica à historiografia, aspecto retomado no

3 A autora justifica o uso de termos como "indústria”, "fábrica”, “manufatura”, entre outros vocábulos, com base nos dicionaristas. Vide p. 140. 
quinto capítulo, que diz respeito à atribuição do fracasso da fábrica à baixa qualidade do minério ou à pobreza das minas. Estudos e alguns relatos da época comprovaram a excelente qualidade do metal produzido, bem como a abundância de recursos naturais. Não obstante, como parte da política de povoamento e de interiorização empreendida pelo governo luso na região, a fábrica de ferro foi infrutífera por causa das "condições de vida" nos sertões, da "falta de mantimentos”, das frequentes sezões, do malogro das lavouras e da "vida dura no trabalho" , fatores que tornaram a povoação industrial um "sorvedouro de gentes” (p. 172). Todavia, Sousa Coutinho tentou exaltar o sucesso da sua política de povoamento, mas ocultando que a principal mão de obra utilizada era a dos centro-africanos, mesmo que soubesse da qualidade do metal que produziam.

O trabalho e os trabalhadores propriamente ditos compõem o tema central do terceiro capítulo, especialmente as múltiplas tensões em torno do controle do trabalho dos ambundos. Ao mesmo tempo, as estratégias utilizadas pelos chefes locais para manter o seu domínio sobre a atividade mineradora foram cruciais, a exemplo da contestação ao pagamento dos dízimos, tributos devidos por contratos celebrados com a coroa portuguesa. ${ }^{4}$ Os chefes africanos tinham a obrigação de enviar seus dependentes para 0 trabalho na fábrica, além de pagarem dízimos. Estas obrigações foram questionadas pelos sobas ao reclamarem dos abusos na cobrança dos tributos, levando-os a propor a isenção do pagamento em troca do trabalho de seus dependentes. Este questionamento gerou um processo de revisão por parte do governador de Angola em relação às obrigações dos sobas. Segundo Alfagali: "Esse percurso burocrático é o resultado de uma estratégia bem-sucedida das lideranças africanas no intuito de proteger seus interesses e conquistar e garantir direitos" (p. 182). Isto significa que a ação dos sobas vassalos modificou a política do governo

4 Os chefes africanos que se tornavam vassalos do rei de Portugal ficaram obrigados a numerosos deveres que incluíam o pagamento de tributos. O pagamento do tributo era prova do reconhecimento do estatuto de vassalo. Beatrix Heintze, Angola nos séculos XVI e XVII. Estudos sobre fontes, métodos e história, Luanda: Kilombelombe, 2007, p. 438. 
português sobre os trabalhadores. Não quer dizer que as vexações se encerraram, pois, "ao corrigir um abuso, nos termos jurídicos da época, os agentes coloniais criaram novos mecanismos para explorar o trabalho de africanos livres; no caso, o trabalho constrangido com a isenção dos dízimos” (p. 191).

Mas o protagonismo africano mais uma vez garantiu margens de manobra, pois os sobas tinham consciência da dependência dos portugueses em relação aos trabalhadores que lhes eram fornecidos e por isso mesmo, frequentemente, a fim de fugir dos abusos, descumpriam as determinações dos funcionários régios. Um bom exemplo apresentado por Alfagali sobre essas tensões é o abandono dos serviços na fábrica por parte de 37 autoridades locais. Este “corpo mole” significou a suspensão do envio de mais "filhos dependentes" por parte dos sobas, que preferiram voltar a pagar dízimos. Adicionalmente, os próprios “filhos” enviados pelos sobas para o serviço nas fábricas fugiam. Mesmo sendo juridicamente livres, eles tinham obrigações e laços de dependência para com os seus anciãos, daí se dizer que "fugiam”. Assim, a desobediência aos "que controlavam a vida política e econômica de sua linhagem não era apenas uma afronta aos espíritos dos antepassados; representava a perda de importantes conexões" e riscos de escravização legal ou ilegal (p. 232). ${ }^{5}$ Porém, mesmo correndo esse risco, alguns filhos preferiram fugir do trabalho na fábrica.

Sousa Coutinho intentava construir uma fábrica nos moldes europeus e não reconhecia a capacidade africana de fabricar ferro. Por isso, buscou a mão de obra que ele considerava especializada, cooptando para essa aventura artesãos europeus e brasílicos. Estratégia que também falhou, como evidenciado no capítulo 4 do livro. Para fazer

5 Sobre as mudanças nos parâmetros de cativos, ver Linda Heywood, "Slavery and Its Transformation in the Kingdom of Kongo: 1491-1800", The Journal of African History, n. 50 (2009), pp. 1-22; Roquinaldo Ferreira, Cross-Cultural Exchange in the Atlantic World: Angola and Brazil During the Era of the Slave Trade, Nova York: Cambridge University Press, 2012; e Mariana Candido, “O limite tênue entre liberdade e escravidão em Benguela durante a era do comércio transatlântico”, Afro-Ásia, n. 47 (2013), pp. 239-268. 
tal diagnóstico, Alfagali analisa, de forma comparativa, os conhecimentos de metalurgia de ferreiros ambundos, portugueses e biscainhos. Um primeiro aspecto que merece atenção diz respeito ao fato de o ofício da fundição e da forja de ferro diferenciar socialmente os ambundos pelos seus significados cosmológicos, sociais, econômicos e políticos, um verdadeiro complexo cultural. A partir desta premissa, Alfagali considera como o domínio dos chefes locais da Ilamba sobre seus dependentes estava estritamente relacionado com um conjunto de mitos que envolviam os ofícios de ferreiros e fundidores. Interessava aos sobas ter entre os seus dependentes "aqueles que, por poderes mágico-religiosos, legitimassem sua autoridade, seja participando de rituais específicos, seja produzindo emblemas de poder" (p. 255). Lembremos que em sociedades centro-africanos a quantidade de dependentes legitimava o poder dos chefes. $^{6}$ Ademais, interessava

6 Entre outros, vide Joseph Miller, Way of Death: Merchant Capitalism and the Angolan Slave Trade, 1730-1830, Madison: University of Wisconsin Press, 1988; John K. Thornton, A África aos "sobas", "ilamba" e "imbari" a colaboração com o projeto de Sousa Coutinho pela possibilidade de obtenção de outros símbolos de distinção social, a exemplo das patentes militares expedidas pelos portugueses. $^{7}$

Nesse sentido, Sousa Coutinho não valorizou o conhecimento e a técnica dos ambundos, pois para ele a produção de ferro era pouca, mesmo que reconhecesse a boa qualidade do metal. Para Alfagali, tratava-se de um olhar preconceituoso que prejudicava os objetivos econômicos dos próprios agentes coloniais. Ao classificar as técnicas africanas como ineficazes, o governo português empregou trabalhadores de outras localidades. A descrição das técnicas utilizadas pelos europeus comprova que as africanas eram as mais exitosas para o meio local. Isto significa que a circulação de saberes entre os trabalhadores africanos e europeus não

e os africanos na formação do mundo atlântico, Rio de Janeiro: Campus, 2004.

7 Sobre a concessão de patentes militares para autoridades africanas, ver Ariane Carvalho, "Guerras nos sertões de Angola: sobas, guerra preta e escravização (1749-1797)”, Tese de Doutorado em História, Universidade Federal do Rio de Janeiro, Rio de Janeiro, 2020. 
foi bem sucedida, apesar de a própria autora indicar que a convivência entre ambos os grupos levou ao aprendizado de outras funções e à incorporação de ferramentas europeias por parte dos africanos. Mas o contrário não se deu.

Ao fim e ao cabo, Nova Oeiras fracassou e, como aponta a autora, esta constatação é um consenso na historiografia. São múltiplas as versões sobre o malogro, e este é o tema debatido no quinto e último capítulo. O sucessor de Sousa Coutinho no governo de Angola, Antonio de Lencastre (1772-1779), decidiu não levar adiante o projeto de Nova Oeiras e teceu duras críticas aos custos da empreitada. É a partir daí que a autora critica a historiografia que pesou somente a decisão de Lencastre como fator crucial para o fechamento de Nova Oeiras, experimento que durou sete anos (1765 - 1772). ${ }^{8}$ Alfagali defende que a análise do fracasso deve considerar a dinâmica

8 Ana Madalena Trigo de Sousa, "D. Francisco de Sousa Coutinho em Angola: reinterpretação de um governo 17641772”, Dissertação de Mestrado em História, Universidade Nova de Lisboa, 1996; e Catarina Madeira Santos, “Um governo 'polido' para Angola. Reconfigurar dispositivos de domínio (1750 - c.1800)”, Tese (Doutorado em História), Universidade Nova de Lisboa, 2005. interna centro-africana. Foram a lógica interna, os diversos agentes envolvidos, as decisões tomadas pelos africanos, as negociações fracassadas, as restrições técnicas aos europeus, entre outros aspectos analisados nos capítulos anteriores, que levaram ao malogro da empreitada. Assim, os trabalhadores africanos são os protagonistas do fracasso português. As técnicas africanas, $\mathrm{o}$ produto in natura e o ferro forjado eram de qualidade inegável. Mas apesar da tentativa de controle pelo governo luso do processo de trabalho dos ambundos, os sobas e seus dependentes "defenderam a autonomia de seu modo de vida” (p. 358).

Com um arcabouço teórico-metodológico robusto, o mérito da investigação de Crislayne Alfagali é incontestável. Seu franco diálogo com a historiografia, a densa análise de fontes, as perguntas que faz, a originalidade do tema e um olhar que prioriza a perspectiva local, tornam Ferreiros $e$ fundidores da Ilamba uma contribuição de peso para os estudos da África Centro-Ocidental. Resta saber, todavia, como os centro-africanos entendiam a categoria trabalho, a fim de que o leitor possa avaliar se 
se trata, ou não, de mais uma leitura eurocêntrica da história africana, posto que a autora segue a tradição teórica da história social do trabalho, de que Edward Thompson e Eric Hobsbawm são os principais representantes. Com efeito, a obra realça com maestria as relações de trabalho na fábrica de ferro, mas fica o questionamento, por exemplo, sobre as esferas de poder e de exploração do trabalho que permitiam aos sobas arregimentar mão de obra e fornecê-la ao empreendimento. Assim, caberia aferir as perspectivas centro-africanas para além da postura dos ambundos frente aos anseios portugueses. A ressalva não significa dizer que as contribuições da história social do trabalho não se apliquem, de antemão, à história de povos centro-africanos. Antes, a inovação da proposta convida a refletir sobre acepções centro-africanas de trabalho.

\section{Ariane Carvalho (DD}

Instituto de Pesquisa e Memória Pretos Novos 